\title{
Correction to: The Role of Parent Phase Compliance on the Fatigue Lifetime of Ni-Ti
}

\author{
Craig Bonsignore $^{1} \cdot$ Ali Shamimi ${ }^{1} \cdot$ Tom Duerig $^{1}$
}

Published online: 15 June 2020

(c) ASM International 2020

\section{Correction to:}

Shape Memory and Superelasticity (2019) 5:407-414

https://doi.org/10.1007/s40830-019-00253-2

The last name of author Ali Shamimi was misspelled as "Shamini" in the original article. Please note that the

Publisher's Note Springer Nature remains neutral with regard to jurisdictional claims in published maps and institutional affiliations.

The original article can be found online at https://doi.org/10.1007/ s40830-019-00253-2.

Craig Bonsignore

craig.bonsignore@confluentmedical.com

1 Confluent Medical Technologies, Fremont, CA, USA 